\title{
Synthesis of thin-multiwalled carbon nanotubes by Fe-Mo/ MgO catalyst using sol-gel method
}

\author{
Prashant Dubey ${ }^{1}$, Sang Kyu Choi ${ }^{2}$, Bawl Kim ${ }^{2}$ and Cheol Jin Lee ${ }^{2, \$}$ \\ ${ }^{1}$ Centre of Material Sciences, Institute of Interdisciplinary Studies, University of Allahabad, Allahabad-211002, India \\ ${ }^{2}$ School of Electrical Engineering, Korea University, Seoul 136-713, Korea
}

\author{
Article Info \\ Received 7 January 2012 \\ Accepted 13 February 2012 \\ *Corresponding Author \\ E-mail: cjlee@korea.ac.kr \\ Tel: $+82-2-3290-3216$
}

\section{Open Access}

DOI: http://dx.doi.org/ 10.5714/CL.2012.13.2.099

This is an Open Access article distributed under the terms of the Creative Commons Attribution Non-Commercial License (http://creativecommons.org/licenses/ by-nc/3.0/) which permits unrestricted non-commercial use, distribution, and reproduction in any medium, provided the original work is properly cited.

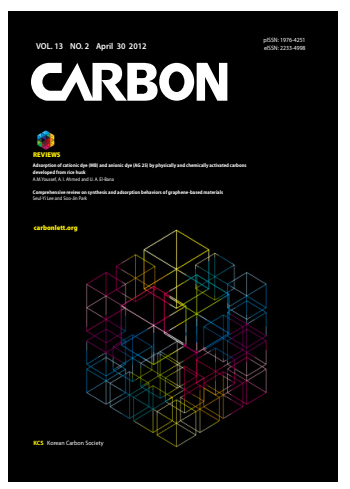

http://carbonlett.org

pISSN: $1976-4251$

eISSN: 2233-4998

Copyright $\odot$ Korean Carbon Society

\begin{abstract}
The sol-gel technique has been studied to fabricate a homogeneous $\mathrm{Fe}-\mathrm{Mo} / \mathrm{MgO}$ catalyst. Ambient effects (air, Ar, and $\mathrm{H}_{2}$ ) on thermal decomposition of the citrate precursor have been systematically investigated to fabricate an $\mathrm{Fe}-\mathrm{Mo} / \mathrm{MgO}$ catalyst. Severe agglomeration of metal catalyst was observed under thermal decomposition of citrate precursor in air atmosphere. $\mathrm{Ar} / \mathrm{H}_{2}$ atmosphere effectively restricted agglomeration of bimetallic catalyst and formation of highly-dispersed $\mathrm{Fe}-\mathrm{Mo} / \mathrm{MgO}$ catalyst with high specific surface-area due to the formation of $\mathrm{Fe}-\mathrm{Mo}$ nanoclusters within $\mathrm{MgO}$ support. High-quality thin-multiwalled carbon nanotubes (t-MWCNTs) with uniform diameters were achieved on a large scale by catalytic decomposition of methane over $\mathrm{Fe}-\mathrm{Mo} / \mathrm{MgO}$ catalyst prepared under Ar-atmosphere. The produced t-MWCNTs had outer diameters in the range of 4-8 $\mathrm{nm}$ (average diameter $\sim 6.6 \mathrm{~nm}$ ) and wall numbers in the range of 4-7 graphenes. The as-synthesized t-MWCNTs showed product yields over $450 \%$ relative to the utilized $\mathrm{Fe}-\mathrm{Mo} / \mathrm{MgO}$ catalyst, and indicated a purity of about $85 \%$.
\end{abstract}

Key words: thermal decomposition, citrate precursor, nanoclusters, thin-multiwalled carbon nanotubes

\section{Introduction}

Thin-multiwalled carbon nanotubes (t-MWCNTs), which have outer diameters of less than $10 \mathrm{~nm}$ and graphene layers of 3-7 numbers, can be considered as an interface between single-walled CNT (SWCNT) and MWCNT structures. Recent experimental results showed that the t-MWCNTs have good electrical and mechanical properties, and excellent electron field emission properties [1-3]. These characteristics make them one of the most promising candidates for bulk applications such as CNT-polymer composites, CNT film, and CNT field emission. There has been a recent flurry of interest by several researchers to synthesize tMWCNTs by catalytic chemical vapor deposition (CCVD) [1,4-6]. In the previous catalyst fabrication methods for t-MWCNT synthesis, a combustion process has commonly been used to obtain $\mathrm{Fe}-\mathrm{Mo} / \mathrm{MgO},[1,4] \mathrm{Ni}-\mathrm{Mo} / \mathrm{MgO}$ [5] or $\mathrm{Co}-\mathrm{Mo} / \mathrm{MgO}$ [6] catalyst materials. To prepare a homogeneous and efficient catalyst, it is desirable to fabricate well dispersed catalyst nanoparticles without agglomeration on the support materials [7-9]. However, there are two major problems for catalyst fabrication using a conventional combustion process: (i) difficulty of the process and poor reproducibility for the fabrication of homogeneous catalyst material due to a very fast and violent combustion process [10], and (ii) severe agglomeration of catalyst nanoparticles during the sintering process at the time of CNT growth.

Several studies have been dedicated to the fabrication of catalyst materials in order to achieve homogeneous and efficient catalyst particles. Coquay et al. [11,12] attempted to obtain a well-dispersed Fe catalyst on an MgO support by urea-combustion. They observed a poorly dispersed metal oxide catalyst, which was responsible for the uncontrolled growth 
of non-homogeneous CNTs. Flahaut et al. [13] reported the formation of ( $\mathrm{Mg}, \mathrm{Co}, \mathrm{Mo}) \mathrm{O}$ solid solutions, which showed large diameter MWCNTs (inner diameter $\sim 9 \mathrm{~nm}$ ) having up to 13 graphene walls due to the used of high Mo content. It has commonly been accepted that the addition of Mo within transition metals like $\mathrm{Fe}, \mathrm{Co}$, or $\mathrm{Ni}$ increases the carbon yield and induces large diameter MWCNTs with defective structures at the side walls [5,13-17]. The realization of highly homogeneous catalyst nanoparticles with uniform size using a simple and low cost process is still a hot issue. Thus, we have studied a way to solve these problems using the sol-gel method. Unlike the highly exothermic combustion process, the sol-gel method is easy and simple to control and suitable for scale-up to the kilogram level [18]. In general, the sol-gel process involves the evolution of inorganic networks through formation of a colloidal suspension (sol) and gelation of the sol to form a three dimensional network in a continuous liquid phase (gel). In a recent paper we reported the synthesis and field emission properties of highquality t-MWCNTs over an $\mathrm{Fe}-\mathrm{Mo} / \mathrm{MgO}$ catalyst based on the sol-gel technique [19]. With the extension of our previous work, we report here details about the fabrication and characterization of well-dispersed and homogeneous Fe-Mo/MgO catalyst materials with effective doping of high Mo content based on a sol-gel precursor method for the synthesis of high-quality t-MWCNTs. The conceptual idea originates from the shielding effect of Mo, which protects against agglomerations of $\mathrm{Fe}$ nanoparticles by effectively forming Fe-Mo nanoclusters that are well-dispersed within the $\mathrm{MgO}$ catalyst support. The purpose of the present report is to investigate the influence of gaseous atmosphere during thermal decomposition of a citrate precursor to fabricate $\mathrm{Fe}-\mathrm{Mo} /$ $\mathrm{MgO}$ catalyst for high-quality t-MWCNT growth.

\section{Experimental section}

\subsection{Preparation and characterization of $\mathrm{Fe}-\mathrm{Mo} /$ MgO catalysts}

The catalysts were prepared by a citrate precursor based on the sol-gel technique using $\mathrm{MgO}$ as catalyst support. An Fe-Mo/ $\mathrm{MgO}$ catalyst was prepared according to the following procedure: the desired amount of $\mathrm{Fe}\left(\mathrm{NO}_{3}\right)_{3} \cdot 9 \mathrm{H}_{2} \mathrm{O}$ (99.99\%, Aldrich) and $\mathrm{Mg}\left(\mathrm{NO}_{3}\right)_{2} \cdot 4 \mathrm{H}_{2} \mathrm{O}(99.99 \%$, Aldrich) were dissolved in $20 \mathrm{~mL}$ deionized (DI) water. Then, citric acid was added as a complexing agent at a ratio of metal ion to citric acid of 1:1.2, followed by the addition of $\left(\mathrm{NH}_{4}\right)_{6} \mathrm{Mo}_{7} \mathrm{O}_{24} \cdot 4 \mathrm{H}_{2} \mathrm{O}$ (Aldrich) as Mo source. After stirring the heterogeneous mixture at $90^{\circ} \mathrm{C}$ for $30-40 \mathrm{~min}$, a very homogeneous solution was obtained. In our experimental conditions, a mole ratio of Fe:Mo: $\mathrm{MgO}=1: 1.5: 10$ was the best composition to obtain homogeneous t-MWCNTs. The homogeneous solution was slowly evaporated on a hot plate to form a viscous gel. Then, the gel was kept for drying at $120^{\circ} \mathrm{C}$ in an oven for $5 \mathrm{~h}$ to remove the adsorbed water. During this process, the gel swelled into a yellow colored fluffy mass (which we call in this paper the 'citrate precursor'). The citrate precursor was then ground into a fine powder. Finally, the citrate precursor was thermally decomposed under air, $\mathrm{Ar}$ (500 sccm), and $\mathrm{H}_{2}$ (500 $\mathrm{sccm}$ ) atmosphere at $700^{\circ} \mathrm{C}$ for $2 \mathrm{~h}$ in a quartz tube furnace to obtain $\mathrm{Fe}-\mathrm{Mo} / \mathrm{MgO}$ catalyst materials for CNT growth.
Powder X-ray diffraction (XRD, Rigaku D/MAX Rint 2000, diffractometer) analysis of the catalyst materials was carried out at room temperature using $\mathrm{Cu} \mathrm{K \alpha}$ radiation $(1.5418 \AA)$ and a graphite secondary beam monochromator. The samples were mounted on a glass plate for X-ray measurements. Intensity was measured by a step scan in the $2 \theta$ range of $10-80^{\circ}$ with a step of $0.05^{\circ}$ and by a measuring time of $5 \mathrm{~s}$ per point.

Nitrogen adsorption-desorption isotherms were measured at $77 \mathrm{~K}$ with an automatic vapor adsorption measurement system, BEL SorpMax, after outgassing at $10^{-3} \mathrm{~Pa}$ for $12 \mathrm{~h}$ at $120^{\circ} \mathrm{C}$. These isotherms provided the Brunauer-Emmett-Teller (BET) specific surface area, pore volume, and pore size analysis of $\mathrm{Fe}$ $\mathrm{Mo} / \mathrm{MgO}$ catalyst materials.

The chemical state of the Fe-Mo catalysts after calcinations was characterized using X-ray photoelectron spectroscopy (XPS, VG-scientific ESCALAB 250 spectrometer) equipped with Al-K $\alpha$ radiation with a photon energy of $1486.6 \mathrm{eV}$. To decrease the influence of oxidation and the contamination of the XPS samples, these catalyst materials were sealed in a plastic box filled with Ar gas as soon as they were removed from the furnace; materials were then transferred to an analysis chamber $\left(2.0 \times 10^{-9}\right.$ torr $)$ through a loading chamber $\left(5.3 \times 10^{-9}\right.$ torr $)$ for XPS measurements.

\subsection{Synthesis and characterization of CNTs}

The synthesis of t-MWCNTs was carried out in a quartz tube reactor (10 cm i.d. and $120 \mathrm{~cm}$ length) mounted in a tube furnace. An amount of $0.1 \mathrm{~g}$ of calcined catalyst was placed into a quartz boat at the center of the reactor tube and heated to the reaction temperature $\left(900^{\circ} \mathrm{C}\right)$ in $\operatorname{an} \operatorname{Ar}(1000 \mathrm{sccm})$ atmosphere. Once the temperature reached $900^{\circ} \mathrm{C}$, the catalyst was pretreated for $20 \mathrm{~min}$ in an $\mathrm{Ar} / \mathrm{H}_{2}(800 / 200 \mathrm{sccm})$ stream. Immediately after this pretreatment, the mixture of $\mathrm{Ar} / \mathrm{CH}_{4} / \mathrm{H}_{2}(1000 / 1000 / 200$ $\mathrm{sccm}$ ) was supplied into the tube reactor at $900^{\circ} \mathrm{C}$ for $30 \mathrm{~min}$ in order to synthesize CNTs. Finally, the reactor was cooled to room temperature in an $\operatorname{Ar}(500 \mathrm{sccm})$ stream. These products are referred to hereafter as as-synthesized t-MWCNTs. The carbon weight-gain of each $\mathrm{Fe}-\mathrm{Mo} / \mathrm{MgO}$ catalyst has been calculated using the following Eq. (1):

$$
\mathrm{C}_{\text {weight-gain }}(\%)=\left[\left(\mathrm{w}_{\text {tot }}-\mathrm{w}_{\text {cat }}\right) / \mathrm{w}_{\text {cat }}\right] \times 100
$$

where $\mathrm{w}_{\text {cat }}$ is the weight of the catalyst before the CNT growth and $\mathrm{w}_{\text {tot }}$ is the total weight of the catalyst and carbon material after the CNT growth.

The morphologies and microstructures of the as-synthesized carbon materials over the $\mathrm{Fe}-\mathrm{Mo} / \mathrm{MgO}$ catalysts synthesized by thermal decomposition of citrate precursor under various atmospheres were initially characterized by scanning electron microscopy (SEM, Hitachi S-4700), operated at an accelerating voltage of $15 \mathrm{kV}$. Samples were deposited onto conductive carbon tape, which was attached to the surface of the SEM brass stub. These samples were then conductively coated with platinum by sputtering for $20 \mathrm{~s}$ to minimize charging effects under SEM imaging conditions.

Transmission electron microscopy (TEM, JEOL JEM-2100F) was used to analyze the quality and structural parameters, such as diameter and wall number, of the CNTs obtained over differ- 
ent catalysts. Samples were prepared by drying a few droplets of the as-synthesized carbon product from an ethanolic dispersion onto a 300 mesh holey $\mathrm{Cu}$ grid coated with a lacey carbon film. TEM and high resolution TEM (HRTEM) images were obtained at accelerating voltages of $120 \mathrm{kV}$ and $200 \mathrm{kV}$, respectively.

Thermogravimetric analysis (TGA) data were collected with a TA Q50 instrument to determine the carbon content and purity of the as-synthesized products. Approximately $5.0 \mathrm{mg}$ of the assynthesized carbon product was placed in a platinum pan and the experiment was performed in a flowing air environment at $30 \mathrm{~mL} / \mathrm{min}$ with a heating rate of $5^{\circ} \mathrm{C} / \mathrm{min}$.

Raman spectra of the as-synthesized carbon products without any purification were recorded using an excitation wavelength of $514.5 \mathrm{~nm}$ on a Raman spectrometer from Horiba Jobin-Yvon, HR-800, equipped with an Olympus confocal microscope. The final spectrum presented was an average of 5 spectra recorded in different regions over the entire range of the samples.

\section{Results and Discussion}

\subsection{Citrate precursor (sol-gel) process}

We adopted the sol-gel method to fabricate the Fe-Mo/ $\mathrm{MgO}$ catalyst for the synthesis of t-MWCNTs. The success of the sol-gel method mainly depends on the quality of the precursor solution. In our catalyst fabrication, $\mathrm{Mg}\left(\mathrm{NO}_{3}\right)_{2} \cdot 4 \mathrm{H}_{2} \mathrm{O}$, $\mathrm{Fe}\left(\mathrm{NO}_{3}\right)_{3} \cdot 9 \mathrm{H}_{2} \mathrm{O}$ and citric acid were dissolved in DI water. The $\mathrm{pH}$ of this solution was found to be about 1.0; the initial color of the solution was orange-red. $\left(\mathrm{NH}_{4}\right)_{6} \mathrm{Mo}_{7} \mathrm{O}_{24} \cdot 4 \mathrm{H}_{2} \mathrm{O}$ was added to the orange-red solution. After stirring the heterogeneous mixture at $90^{\circ} \mathrm{C}$ for $30-40 \mathrm{~min}$, there was a dissolution of the molybdenum complex. The reaction could presumably be a complex formation between an aqueous solution of molybdate $\left(\mathrm{MoO}_{4}{ }^{2-}\right)$ and citric acid at that acidic $\mathrm{pH}$. The complex formation between $\mathrm{MoO}_{4}{ }^{2-}$ and citrate is well-known in different $\mathrm{pH}$ ranges [20]. The reaction is shown in Eq. (2):

$$
\mathrm{MoO}_{4}^{2-}+\text { Citric acid } \rightarrow \text { Citratomolybdate complex }
$$

In terms of chemical composition, the citrate precursor is obtained from the aqueous solution containing $\mathrm{Mg}^{2+}, \mathrm{Fe}^{3+}$, and $\mathrm{Mo}^{6+}$ metal salts and polyfunctional citric acid. The hydroxyl and carboxylate functional groups in the citric acid (containing 1 hydroxyl and 3 carboxylate groups per molecule) react chemically with the metal ions to form a complex or a precursor. The structure of the precursor and the composition (metal: ligand) may depend on the $\mathrm{pH}$ of the solution. But for our purposes it is assumed that one mole of citric acid binds with one mole of metal ions (1:1). The citrate precursor solution was further heated with constant stirring at $90^{\circ} \mathrm{C}$ to form a gel. The transformation of the sol to a semi-solid type gel was visible at this stage. The gel was kept at $120^{\circ} \mathrm{C}$ in the oven for $5 \mathrm{~h}$ to obtain a very homogeneous yellow colored fluffy solid. In our sol-gel precursor method, it should be mentioned here that the function of the complexing agent (citric acid) is threefold: (i) stabilizing the precursor solution through formation of metal hydroxo complexes during the gel formation; (ii) preventing precipitation of $\mathrm{MoO}_{4}{ }^{2-}$ in the form of $\mathrm{MoO}_{3}$ due to formation of stable citra-

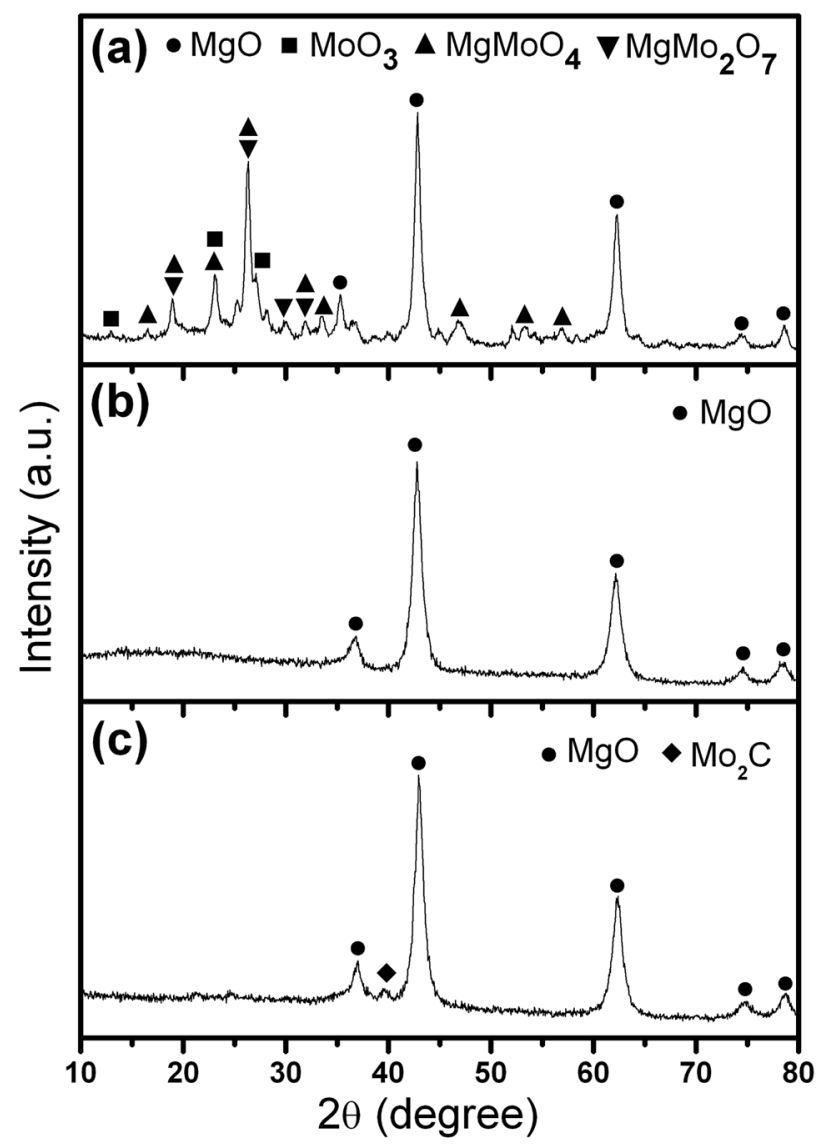

Fig. 1. X-ray diffraction patterns of Fe-Mo/MgO catalyst synthesized by thermal decomposition of the citrate precursor at $700^{\circ} \mathrm{C}$ for $2 \mathrm{~h}$ : (a) SG-1, (b) SG-2 and (c) SG-3 catalyst.

tomolybdate complexes (Eq. 2) at acidic pH; and (iii) acting as a foaming agent to produce a large volume of fluffy solid (citrate precursor). The $\mathrm{Fe}-\mathrm{Mo} / \mathrm{MgO}$ catalyst was prepared by thermal decomposition of a citrate precursor at $700^{\circ} \mathrm{C}$ for $2 \mathrm{~h}$ under various atmospheres to evaluate the structure and the homogeneity of the produced nanotubes; these atmospheres were an oxidizing atmosphere such as 'air' (SG-1), an inert atmosphere such as 'Ar' (SG-2), and a reducing atmosphere such as ' $\mathrm{H}_{2}$ ' (SG-3).

\subsection{Characterization of Fe-Mo/MgO catalysts}

Powder XRD and BET surface area analyses were carried out for all three $\mathrm{Fe}-\mathrm{Mo} / \mathrm{MgO}$ catalyst materials synthesized by thermal decomposition of the citrate precursor under different atmospheres. Fig. 1 shows the combined XRD patterns of the three sol-gel catalysts (SG-1, SG-2 and SG-3). The XRD pattern clearly shows the five well-resolved characteristic peaks of the $\mathrm{MgO}$ rock-salt lattice in all three samples [21]. We were not able to detect any separate phase for $\mathrm{Fe}_{2} \mathrm{O}_{3}$ or $\mathrm{MoO}_{\mathrm{x}}$ from SG-2 and SG-3 catalysts (Figs. $1 \mathrm{~b}$ and c), which means that the Fe and Mo species have good dispersion within the $\mathrm{MgO}$ matrix. For an ideal $\mathrm{FeO}-\mathrm{MgO}$ solid solution, all iron should be in the divalent state and should substitute for $\mathrm{Mg}^{2+}$ [11]. As the ionic radius of $\mathrm{Fe}^{2+}$ is larger than the ionic radius of $\mathrm{Mg}^{2+}, \mathrm{FeO}-\mathrm{MgO}$ 


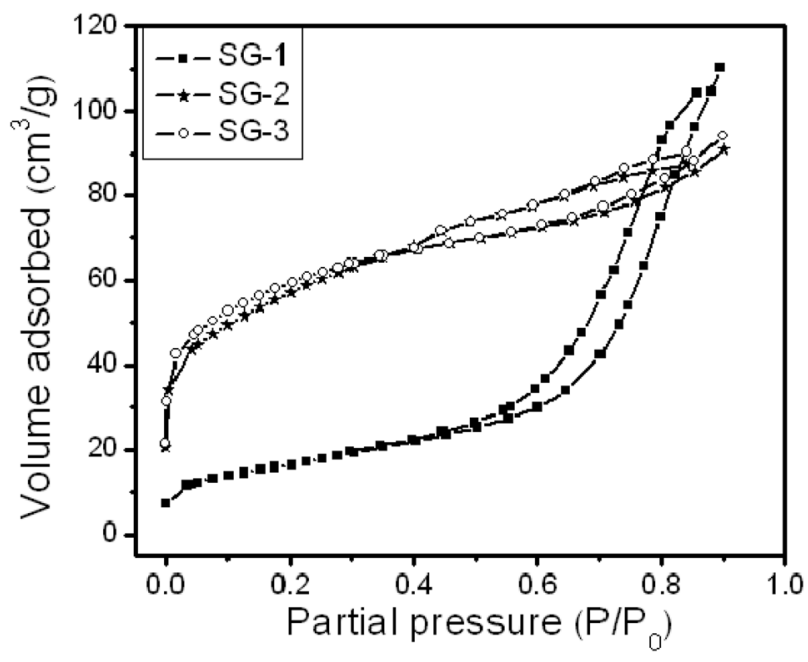

Fig. 2. Nitrogen adsorption and desorption isotherms of $\mathrm{Fe}-\mathrm{Mo} / \mathrm{MgO}$ catalyst materials synthesized by thermal decomposition of citrate precursor at $700^{\circ} \mathrm{C}$ for $2 \mathrm{~h}$.

solid solution is unfavorable for the high dispersion of Fe species compared to $\mathrm{CoO}-\mathrm{MgO}$ or Ni-MgO solid solutions [22]. Here, we propose that $\mathrm{Fe}$ forms a stable cluster with Mo, and it exists predominantly in the $\mathrm{Fe}^{3+}$ state. Principally, these $\mathrm{Fe}-\mathrm{Mo}$ clusters are anionic in nature and can strongly interact within the $\mathrm{Mg}^{2+}$ lattice to favor well-dispersed nanoparticles in the form of $\mathrm{Fe}-\mathrm{Mo} / \mathrm{MgO}$. This hypothesis will be supported in the later section by TEM-energy dispersive X-ray spectrometer (EDS) and XPS studies. The XRD pattern of the SG-1 catalyst clearly showed different Mo phases such as $\mathrm{MgMoO}_{4}, \mathrm{MgMo}_{2} \mathrm{O}_{7}$, and $\mathrm{MoO}_{3}$ (Fig. 1a) which are invisible in the SG-2 and SG-3 catalysts [17,23]. In the case of the SG-3 catalyst, we observed the $\mathrm{Mo}_{2} \mathrm{C}$ phase from XRD (Fig. 1c); this phase may be attributed to the reducing $\mathrm{H}_{2}$ atmosphere and the carbon supply from the burning of the citric acid at $700^{\circ} \mathrm{C}$ [24]. Thus, from XRD analysis, it is understood that $\mathrm{Fe}-\mathrm{Mo} / \mathrm{MgO}$ catalysts produced by thermal decomposition of the citrate precursor under Ar and $\mathrm{H}_{2}$ atmosphere are well-mixed bimetallic catalysts compared to those catalysts produced in an air atmosphere.

Fig. 2 shows the nitrogen adsorption and desorption isotherms of the three $\mathrm{Fe}-\mathrm{Mo} / \mathrm{MgO}$ catalyst materials synthesized by decomposition of the citrate precursor. The $\mathrm{Fe}-\mathrm{Mo} / \mathrm{MgO}$ catalyst with $\mathrm{Ar}$ or $\mathrm{H}_{2}$ decomposition atmosphere (SG-2 and SG-3) exhibits an isotherm with a well-developed step in the relative pressure range of $0.4-0.85$, a characteristic of capillary filling into the uniform mesopores [25]. However, the Fe-Mo/MgO catalyst with an air atmosphere (SG-1) broadens the pore distribu- tion. The isotherm therefore indicates that both SG-2 and SG-3 catalysts possess good structural ordering and a narrow pore size distribution compared to those of the SG-1 catalyst. The difference observed in the adsorption isotherm of the $\mathrm{Fe}-\mathrm{Mo} / \mathrm{MgO}$ catalysts is attributed to the difference in the preparation conditions. The $\mathrm{Ar}$ or $\mathrm{H}_{2}$ atmosphere induces uniform sized Fe-Mo bimetallic catalysts with homogeneous distribution within $\mathrm{MgO}$ pores; air atmosphere, on the other hand, leads to a non-uniform Fe-Mo catalyst.

The BET surface area, pore diameter and pore volume of Fe$\mathrm{Mo} / \mathrm{MgO}$ catalysts are also found to depend on the decomposition atmosphere of the citrate precursor. The results are summarized in Table 1. It can be observed that the BET surface area of the SG-1 catalyst material is very low compared to that of the SG-2 or SG-3 catalysts. The surface areas observed for the SG-2 or SG-3 catalyst materials are comparable. Furthermore, air decomposition of the citrate precursor leads to a large pore diameter and pore volume for the $\mathrm{Fe}-\mathrm{Mo} / \mathrm{MgO}$ catalyst. We also examined the surface properties of a material with only $\mathrm{MgO}$ support synthesized in the same conditions except for the addition of Fe and Mo species; this test is shown in the small brackets in Table 1. In an air atmosphere, we observed an increment of pore diameter and pore volume in the $\mathrm{Fe}-\mathrm{Mo} / \mathrm{MgO}$ catalyst (SG1) compared with the material with only $\mathrm{MgO}$ support; however, the surface areas are comparable. This may be attributed to the non-uniform distribution of bimetallic nanoclusters and to phase separation of the catalyst materials due to the formation of $\mathrm{Mg}$ $\mathrm{MoO}_{4} / \mathrm{MgMo}_{2} \mathrm{O}_{7}$; these results further correlate with our XRD results, which were discussed in the previous section. However, $\mathrm{Ar}$ and $\mathrm{H}_{2}$ decomposed $\mathrm{Fe}-\mathrm{Mo} / \mathrm{MgO}$ catalysts (SG-2 and SG-3) showed decreased pore diameter, pore volume, and surface area compared to the case of the $\mathrm{MgO}$ support material. This behavior can be explained as being due to pore filling and the blocking phenomenon of metal precursors [26]; this behavior supports our hypothesis that Fe-Mo systems form in a well-dispersed manner within $\mathrm{MgO}$ support. The product yields of carbon materials were found to be correlated with the BET surface area of the starting $\mathrm{Fe}-\mathrm{Mo} / \mathrm{MgO}$ catalysts. It is generally understood that a large surface area with a small pore size of catalyst material may provide large numbers of active metal catalysts; this is the characteristic that is responsible for the high-yield carbon materials (Table 1). In the case of the SG-1 catalyst, the produced carbon material consisted of thick CNTs and carbon fibers, along with some t-MWCNTs (see later section), which may be explained as being due to the agglomeration of metal nanoparticles due to the large pore size and small surface area of the $\mathrm{Fe}-\mathrm{Mo} / \mathrm{MgO}$ catalyst at $900^{\circ} \mathrm{C}$ growth temperature.

Fig. 3 provides plane views of TEM images of the Fe-Mo/

Table 1. Pore diameter, pore volume and BET surface area of Fe-Mo/MgO catalyst materials and carbon yields obtained on these catalysts based on weight gain measurements (Eq. 1) and TGA analysis (value given within small bracket indicates MgO support material without Fe and Mo content)

\begin{tabular}{cccccc} 
Catalyst materials & Pore diameter $(\mathrm{nm})$ & Pore volume $\left(\mathrm{cm}^{3} / \mathrm{g}\right)$ & Surface area $\left(\mathrm{m}^{2} / \mathrm{g}\right)$ & Product yield $(\%)$ & Carbon \% yield @TGA \\
\hline SG-1 & $11.4(9.2)$ & $0.17(0.13)$ & $60(55)$ & 73 & 43 \\
\hline SG-2 & $2.8(3.3)$ & $0.14(0.22)$ & $202(261)$ & 452 & 85 \\
\hline SG-3 & $2.8(3.3)$ & $0.15(0.20)$ & $210(253)$ & 370 & 82 \\
\hline
\end{tabular}

BET: Brunauer-Emmett-Teller, TGA: thermogravimetric analysis. 

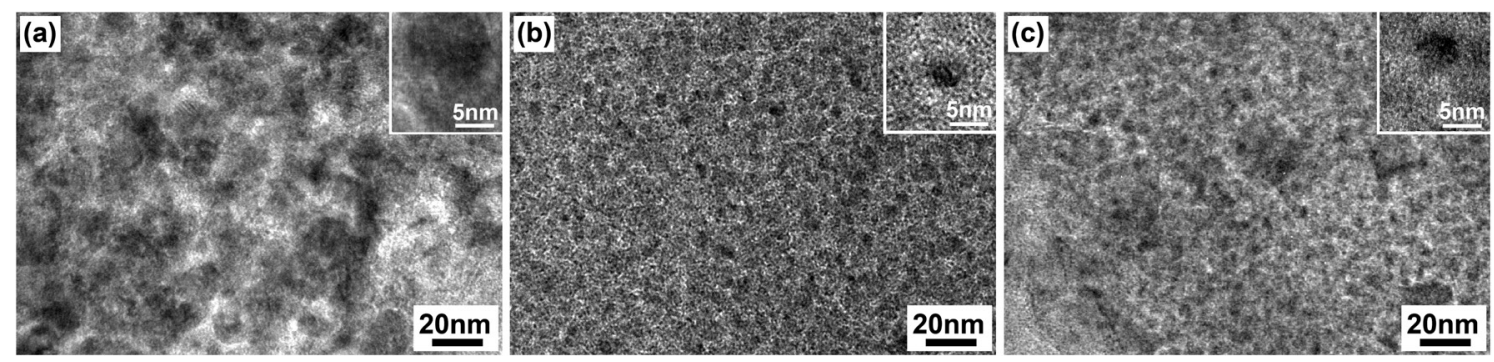

Fig. 3. Low-magnification transmission electron microscope (TEM) images of Fe-Mo/MgO catalyst materials synthesized by thermal decomposition of the citrate precursor at $700^{\circ} \mathrm{C}$ for $2 \mathrm{~h}$ : (a) SG-1, (b) SG-2 and (c) SG-3 catalyst. Insets show high-magnification TEM images of individual catalyst particles.

$\mathrm{MgO}$ catalyst materials prepared by thermal decomposition of the citrate precursor under different atmospheres. In the case of the SG-1 catalyst, we can observe a non-uniform distribution of catalyst particles (dark spots) on the $\mathrm{MgO}$ support material, as shown in Fig. 3a. The TEM observation is consistent with the surface analysis results, in which the SG-1 catalyst shows a low BET surface area and a large pore diameter. On the other hand, we can observe well-dispersed nanosized particles as dark spots in the case of the $\mathrm{Ar}$ (SG-2) and $\mathrm{H}_{2}$ (SG-3) atmospheres, as shown in Figs. $3 \mathrm{~b}$ and c. The size of the dark spots was measured and found to be in the range of 3-6 nm for the SG-2 and SG-3 catalysts (inset of Figs. $3 \mathrm{~b}$ and c). We further analyzed the TEMEDS of the dark spots at a $1.0 \mathrm{~nm}$ target point, which showed a higher atomic $\%$ of Mo compared with that of $\mathrm{Fe}$ in the cases of SG-2 (at\% Fe:Mo 3.1:10.5) and SG-3 (at\% Fe:Mo 3.0:12.1) catalysts, while the atomic $\%$ of $\mathrm{Fe}$ is higher in the case of the SG-1 (at \% Fe:Mo 7.9:4.2) catalyst. Therefore, we conclude that in the case of $\mathrm{Ar}$ and $\mathrm{H}_{2}$ decomposition atmospheres, the formation of $\mathrm{Fe}-\mathrm{Mo}$ nanosized clusters with higher Mo content is predominant and Mo protects against the agglomeration of $\mathrm{Fe}$ nanoparticles. However, in the case of an air decomposition atmosphere, Fe appears to be more actively agglomerated because of the phase separation between Fe and Mo particles and because Mo doesn't react with Fe during the formation of nanoparticles. This result is also supported by XRD, which show well-mixed $\mathrm{Fe}-\mathrm{Mo} / \mathrm{MgO}$ bimetallic catalyst in the case of SG-2 and SG-3 catalysts, while SG-1 showed various Mo phases with strong interaction among $\mathrm{Mg}$ ions.

Fig. 4 shows the Mo 3d core level XPS spectra of the citrate precursor and the $\mathrm{Fe}-\mathrm{Mo} / \mathrm{MgO}$ catalyst materials synthesized after thermal decomposition in various atmospheres. In the case of the citrate precursor (Fig. 4a), the XPS exhibits a pair of spin-orbit binding energies (BEs) at 231.0 and $234.0 \mathrm{eV}$. The Mo $3 \mathrm{~d}_{5 / 2} \mathrm{BE}$ at $231.0 \mathrm{eV}$ is attributed to $\mathrm{Mo}^{6+}$ in the citratomolybdate complex; this value is slightly lower than that of $\mathrm{Mo}^{6+}$ in $\mathrm{MoO}_{3}(232.2-233.0 \mathrm{eV})$ due to the complex formation, whereas the second $\mathrm{BE}$ at $234.0 \mathrm{eV}$ can be assigned to the $\mathrm{Mo} 3 \mathrm{~d}_{3 / 2}$ of the citratomolybdate complex. After thermal decomposition in air (Fig. 4b), a pair of spin-orbit BEs shifted towards higher values at 232.2 and $235.4 \mathrm{eV}$; these values are assigned to $\mathrm{Mo}^{6+}$ in $\mathrm{MoO}_{3}$ or to $\mathrm{MgMo}_{\mathrm{x}} \mathrm{O}_{\mathrm{y}}$ [27]. It can be observed that the XPS of the SG-2 and SG-3 catalysts exhibit a pair of spin-orbit BEs at 231.1 and 234.3-234.4 eV, whereas a new component appeared at 228.3$229.1 \mathrm{eV}$ (Figs. $4 \mathrm{c}$ and d). The Mo $\left(3 \mathrm{~d}_{5 / 2}\right.$ and $\left.3 \mathrm{~d}_{3 / 2}\right)$ BEs at 231.1 and $234.3-234.4 \mathrm{eV}$ can be assigned to the $\mathrm{Mo}^{6+}$ in nanoclusters [28-31]. Interestingly, $\mathrm{Mo}^{6+} \mathrm{BEs}$ in the Mo $3 \mathrm{~d}$ core level of SG-2

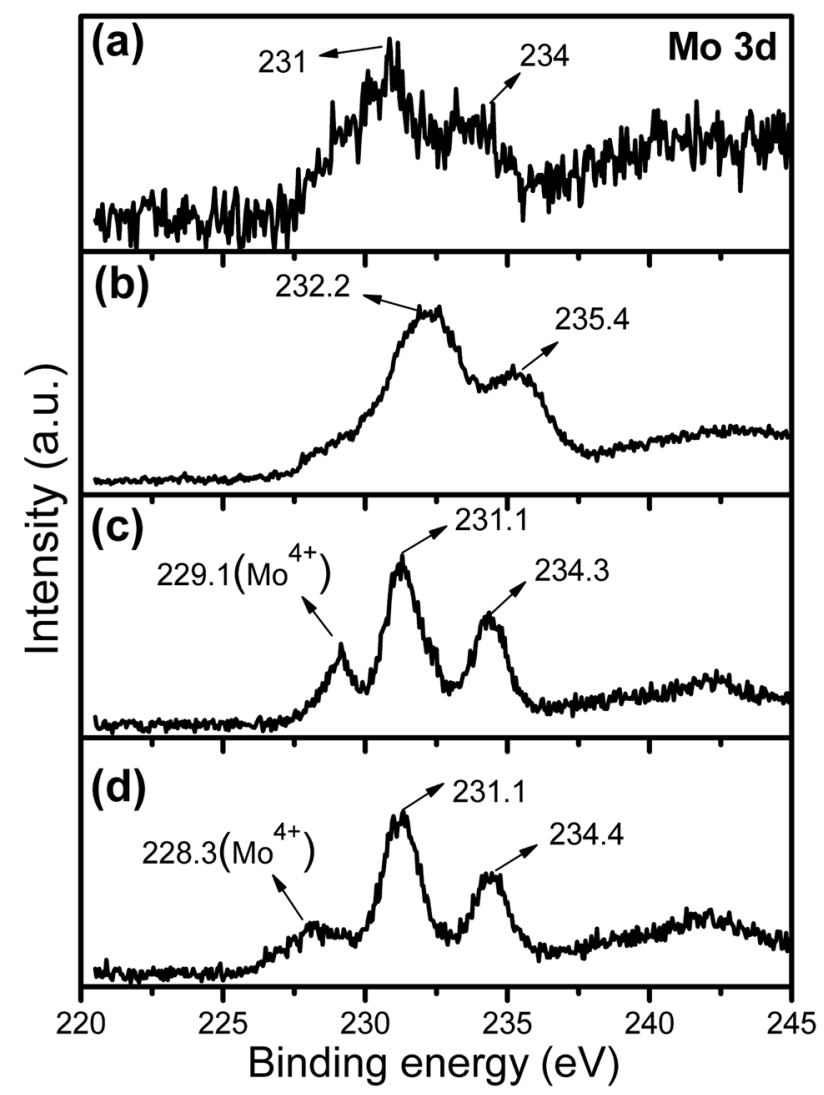

Fig. 4. Mo 3d core level X-ray photoelectron spectroscopy spectra of citrate precursor (a) and $\mathrm{Fe}-\mathrm{Mo} / \mathrm{MgO}$ catalyst materials synthesized by thermal decomposition at $700^{\circ} \mathrm{C}$ for $2 \mathrm{~h}$ : (b) SG-1, (c) SG-2 and (d) SG-3 catalyst.

and SG-3 showed values that were slightly lower than those of the SG-1 catalyst (Fig. 4), which may be explained as in the case of the $\mathrm{Ar}$ and $\mathrm{H}_{2}$ decomposition of the citrate precursor, in which Mo has a strong interaction with Fe. From a chemical point of view, $\mathrm{Fe}^{3+}$ and $\mathrm{Mo}^{6+}$ have strong tendencies to aggregate in the form of a cluster under a reducing atmosphere [32,33]. We consider that Mo provides a shielding effect for the Fe nanoparticles in the form of a nanocluster/alloy to prevent agglomeration at higher growth temperatures. The new Mo $3 \mathrm{~d}_{5 / 2}$ peak at lower BE for SG-2 and SG-3, at around 228.3-229.1 eV, is assigned to $\mathrm{Mo}^{4+} / \mathrm{Mo}^{5+}$ in the nanocluster. So, these results indicate that the decomposition of the citrate precursor in air resulted in the 


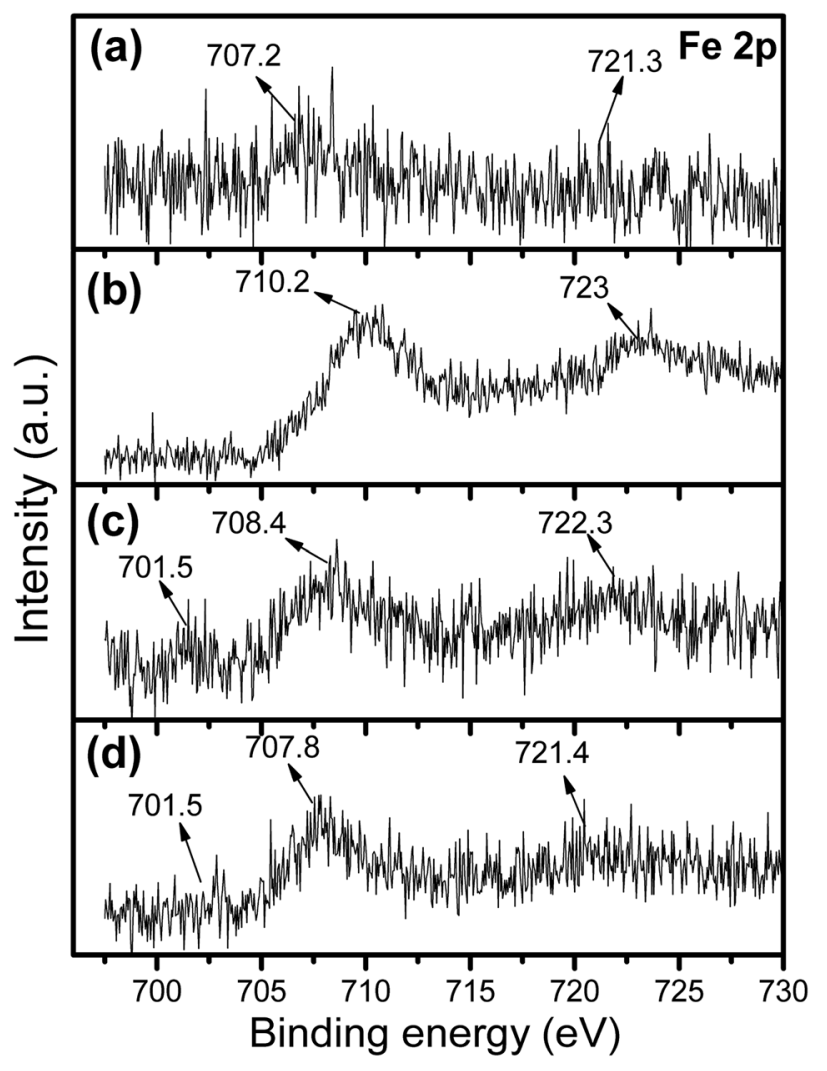

Fig. 5. Fe 2p core level X-ray photoelectron spectroscopy spectra of citrate precursor (a) and $\mathrm{Fe}-\mathrm{Mo} / \mathrm{MgO}$ catalyst materials synthesized by thermal decomposition at $700^{\circ} \mathrm{C}$ for 2 h: (b) SG-1, (c) SG-2 and (d) SG-3 catalyst.

formation of $\mathrm{Mo}^{6+}$ in $\mathrm{MoO}_{3}$ and /or $\mathrm{MgMo}_{x} \mathrm{O}_{\mathrm{y}}$, while the decomposition in $\mathrm{Ar}$ and $\mathrm{H}_{2}$ atmosphere produced $\mathrm{Mo}^{6+}$ and $\mathrm{Mo}^{4+} /$ $\mathrm{Mo}^{5+}$ in the form of nanoclusters. Another important point to note is the linewidth of the XPS spectra (Fig. 4). The linewidths of the Mo $3 \mathrm{~d}$ peaks obtained for the SG-2 and SG-3 catalysts were sharper than that for SG-1. A similar linewidth sharpening phenomenon has been observed for the Co-Mo catalyst system when $\mathrm{Na}$ is doped into the catalyst; the phenomenon is attributed to the formation of sodium molybdate [34]. Here in our experimental conditions, we assigned this to the strong interaction of Mo with Fe and the formation of clusters. Even though this observation cannot be perfectly conclusive, it agrees with the results obtained by XRD and EDS-TEM, which indicate a well-dispersed Fe-Mo bimetallic catalyst within the $\mathrm{MgO}$ matrix and the existence of a higher $\mathrm{Mo} / \mathrm{Fe}$ atomic ratio within the 1.0 nm spot range.

XPS of the Fe $2 p$ core level for the citrate precursor as well as for the $\mathrm{Fe}-\mathrm{Mo} / \mathrm{MgO}$ catalyst materials synthesized by thermal decomposition in various atmospheres are shown in Fig. 5. In the case of the citrate precursor (Fig. 5a), again a pair of spin-orbit BEs at 707.2 and $721.3 \mathrm{eV}$ exhibit very low intensity; their peak intensity increased and shifted towards a higher value at 710.2 and $723.0 \mathrm{eV}$ after thermal decomposition in air (Fig. $5 b$ ). In the case of the SG-1, both peaks are assigned to $\mathrm{Fe}^{3+}$ (as $\mathrm{Fe} 2 \mathrm{p}_{3 / 2}$ and $\mathrm{Fe} 2 \mathrm{p}_{1 / 2}$ ) in $\mathrm{Fe}_{2} \mathrm{O}_{3}$ and/or $\mathrm{FeMoO}_{x}$ [27]. Again, SG-2 (Fig. 5c) and SG-3 (Fig. 5d) showed a pair of spin-orbit BEs
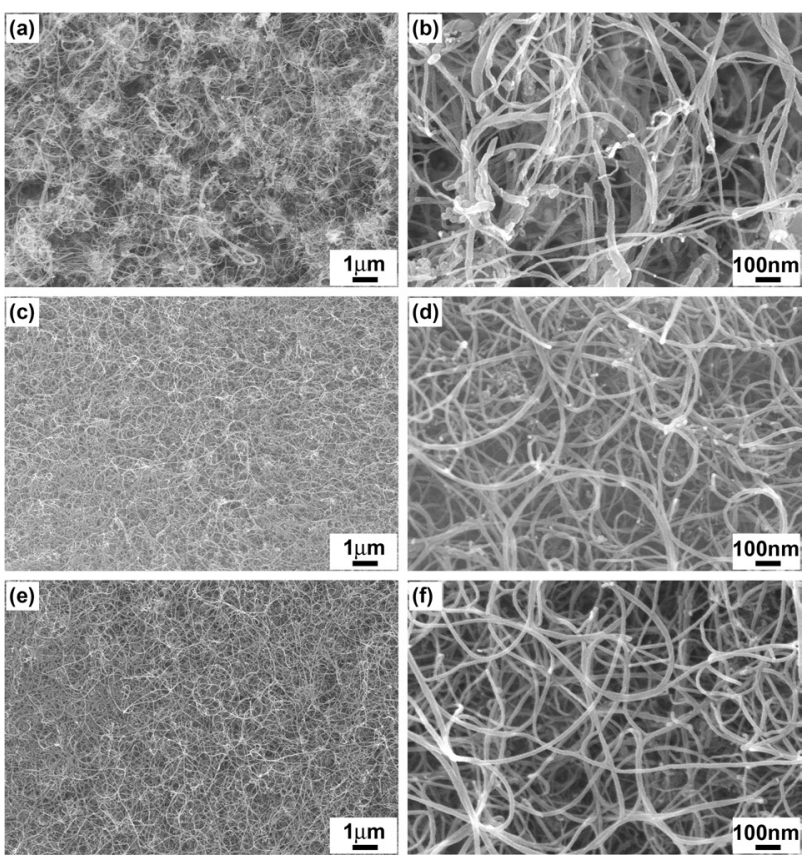

Fig. 6. Low and high-magnification scanning electron microscope images of the as-synthesized carbon materials fabricated by catalytic decomposition of $\mathrm{CH}_{4}$ over Fe-Mo/MgO catalysts: (a, b) SG-1, (c, d) SG-2 and (e, f) SG-3.

at 707.8-708.4 and 721.4-722.3 eV, which can be attributed to $\mathrm{Fe}^{3+}$ (as $\mathrm{Fe} 2 \mathrm{p}_{3 / 2}$ and $\mathrm{Fe} 2 \mathrm{p}_{1 / 2}$ ) in nanoclusters [35,36]. In the case of the $\mathrm{Ar}$ and $\mathrm{H}_{2}$ decomposition, again we observed one peak at a lower $\mathrm{BE}$ of around $701.5 \mathrm{eV}$; this peak is assigned to $\mathrm{Fe}^{2+}$ or even to metallic Fe species in nanoclusters.

\subsection{Characterization of CNTs}

Low and high-magnification SEM images of the as-synthesized carbon products over SG-1, SG-2, and SG-3 catalysts are shown in Fig. 6. It can be observed that the $\mathrm{Fe}-\mathrm{Mo} / \mathrm{MgO}$ catalyst materials synthesized under various thermal decomposition atmospheres strongly influence the CNT growth in terms of CNT morphology and homogeneity. In the case of the SG-1 catalyst, we can observe thick CNTs and fiber like structures along with narrow CNTs (Figs. 6a and b). The formation of carbon nanofiber may be due to the existence of large Fe particles on the catalyst. Mo has a small tendency to mix with $\mathrm{Fe}$ in the form of nanoclusters [12]. On the other hand, SG-2 and SG-3 catalysts produced abundant $\mathrm{CNT}$ products by catalytic decomposition of $\mathrm{CH}_{4}$. The entangled CNTs fully covered the entire catalyst surface and we were hardly able to observe any $\mathrm{MgO}$ support materials (Figs. 6c and e). High-magnification SEM images (Figs. 6d and f) show that the as-synthesized CNTs have uniform diameters and clean surfaces without amorphous carbon impurities. It is noteworthy to mention that no purification was conducted before imaging. Thus, SEM observations qualitatively indicate that the produced CNTs have high yield, high homogeneity, and high purity in the cases of the SG-2 and SG-3 catalysts. To quantify the product yield of the CNTs, a weight gain measurement (Eq. 1) was done for the as-synthesized carbon materials. High 

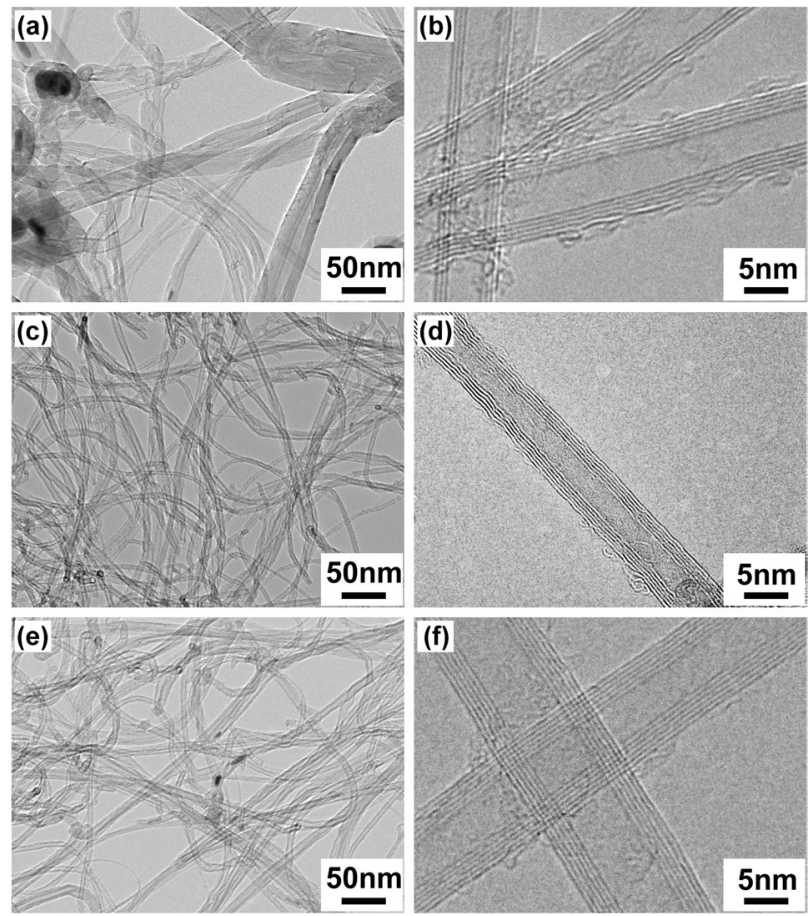

Fig. 7. Typical low-magnification transmission electron microscope (TEM) and high resolution TEM images of the as-synthesized carbon materials fabricated by catalytic decomposition of $\mathrm{CH}_{4}$ over Fe-Mo/MgO catalysts: (a, b) SG-1, (c, d) SG-2 and (e, f) SG-3.

yield of over $450 \%$ of the CNTs was obtained relative to the weight of the utilized SG-2 catalyst, revealing a significantly high product yield of carbon materials (Table 1). In our catalyst composition study, the Fe: Mo ratio was found to be crucial to the achievement of homogeneous t-MWCNTs at high-yield. We obtained the best results at a molar ratio of $\mathrm{Fe}$ : $\mathrm{Mo}=1: 1.5$; it is considered that the good catalyst activity was caused by the effective doping of high Mo content into the catalyst materials. The higher Mo content can provide an effective shielding for $\mathrm{Fe}$ catalyst particles to prevent their agglomeration and to promote the aromatization of $\mathrm{CH}_{4}$ at an elevated temperature. It is wellknown that the supported Mo compounds on zeolite, as well as a transition alumina, convert $\mathrm{CH}_{4}$ into aromatic species [37-39]. For an $\mathrm{Fe}-\mathrm{Mo} / \mathrm{MgO}$ catalyst with a $\mathrm{CH}_{4}$ carbon source at $900^{\circ} \mathrm{C}$, it is plausible that intermediate aromatic hydrocarbons are generated at the Mo sites [40].

Fig. 7 shows TEM images of the as-synthesized carbon materials fabricated by catalytic decomposition of $\mathrm{CH}_{4}$ over various $\mathrm{Fe}-\mathrm{Mo} / \mathrm{MgO}$ catalysts. The carbon material synthesized over the SG-1 catalyst shows a non-uniform CNT structure, which is also confirmed by SEM observations. One can clearly see that a mixture of t-MWCNTs, MWCNTs, and carbon fibers exists in the carbon products using the SG-1 catalyst (Fig. 7a). A representative HRTEM of the SG-1 derived t-MWCNTs is shown in Fig. 7b. On the other hand, a low-magnification TEM image clearly reveals the high-quality t-MWCNTs with uniform diameters synthesized by the SG-2 catalyst (Fig. 7c). Furthermore, SG-3 synthesized t-MWCNTs show homogeneity and other characteristics that are almost identical to those of SG-2 synthesized t-MWCNTs (Figs. 7c and e). In addition, it is very difficult to determine bundle morphology for the t-MWCNTs produced by the SG-2 catalyst; this is different from the case in previous reports, and indicates the mixture of isolated tubes and bundles of tubes $[1,4]$. This may be attributed to the formation of slightly larger diameter t-MWCNTs on the catalyst particles, which introduce a weak van der Waals interaction between the tubes. An HRTEM image of the as-synthesized t-MWCNTs over the SG-2 catalyst clearly indicates the resolved graphene layers and slightly amorphous carbon deposits on the t-MWCNT surface (Fig. 7d). This indicates that the as-synthesized t-MWCNTs are of high-quality. Moreover, the HRTEM observations indicate that the produced high-quality t-MWCNTs have only a few graphene walls in the range of 4 to 7 numbers.

We further evaluated the distributions of the outer diameters and the graphene wall numbers of the t-MWCNTs synthesized by SG-2 and SG-3 catalysts. We measured more than 150 isolated $\mathrm{t}-\mathrm{MWCNTs}$ with an accuracy of about $\pm 0.1-0.15 \mathrm{~nm}$, based on HRTEM images like those in Figs. $7 \mathrm{~d}$ and $\mathrm{f}$. In the case
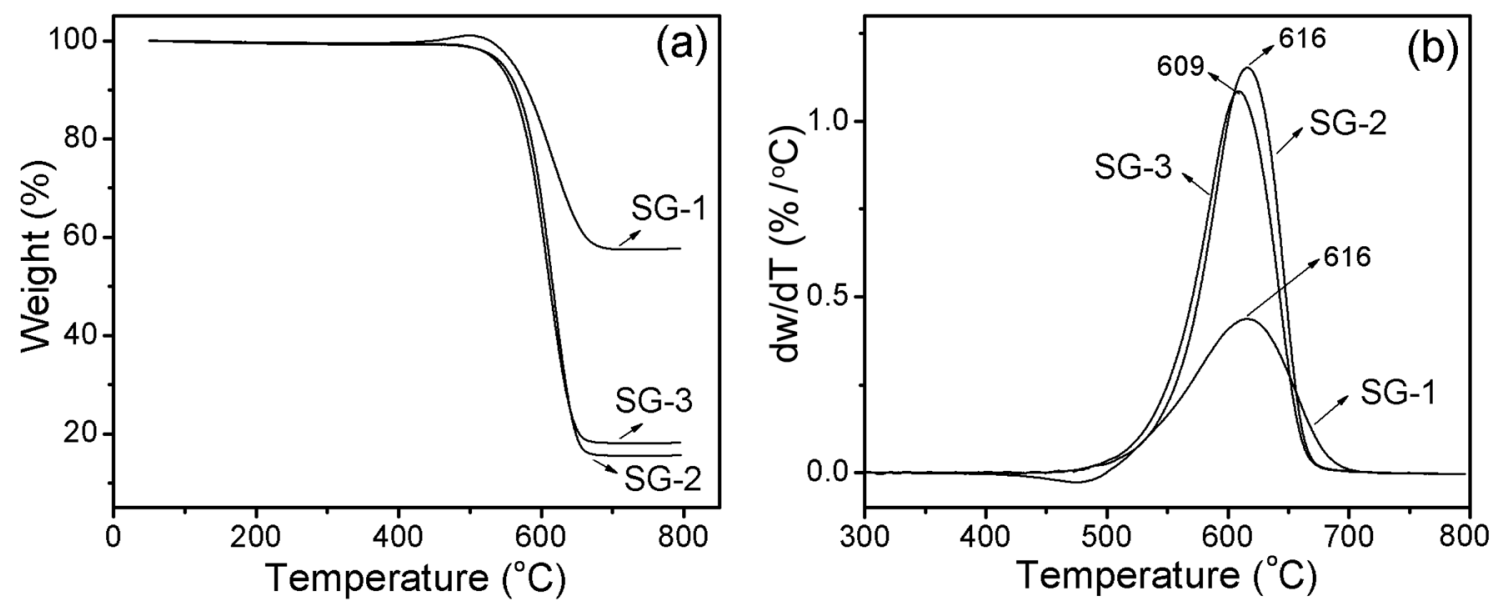

Fig. 8. Thermogravimetric analysis weight loss curve (a) and the corresponding derivative curve (b) of the as-synthesized thin-multiwalled carbon nanotubes fabricated by catalytic decomposition of $\mathrm{CH}_{4}$ over Fe-Mo/MgO catalysts. 
of the SG-2 catalyst, more than $95 \%$ of the t-MWCNTs have outer diameters in the range of 4-8 nm, with a Gaussian mean diameter of $6.6 \pm 0.1 \mathrm{~nm}$; they also have graphene walls with numbers of 4-7. However, in the case of the SG-3 catalyst, most of the t-MWCNTs have outer diameters in the range of 4-9 nm, with a Gaussian mean diameter of $7.7 \pm 0.1$ and graphene walls with number of 5-8. Thus, it is considered that the t-MWCNTs produced by both SG-2 and SG-3 catalysts have homogeneous morphology and structure on top of their uniform diameters. Compared with previous reports on the synthesis of t-MWCNTs, which showed final outer diameter distributions in the range of 3-6 nm using $\mathrm{Fe}-\mathrm{Mo} / \mathrm{MgO}$ combustion catalyst [4], the t-MWCNTs in our report had slightly larger outer diameters, in the range of 4-8 $\mathrm{nm}$. In an earlier report, low Mo content within the bimetallic catalyst $\left(\mathrm{Fe}_{1.0} \mathrm{Mo}_{0.25} \mathrm{Mg}_{8.75} \mathrm{O}\right.$ as catalyst) was used; also, CNT growth was performed in a small-scale reactor under a high flow rate of $\mathrm{H}_{2}$ as a carrier gas [4]. Here it is worth mentioning that we could never have obtained high-yield and homogeneous t-MWCNTs in our experimental conditions using a low Mo concentration catalyst in a large-scale reactor (reactor i.d. $\sim 100 \mathrm{~mm}$ ). Here we consider that the slightly large diameter of our t-MWCNTs is due to the higher Mo concentration [13]. We suggest that the high Mo concentration is beneficial for the efficient decomposition of $\mathrm{CH}_{4}$ and is favorable for the growth of high-yield and homogeneous t-MWCNTs.

TGA analysis was used to determine the carbon content and purity of the as-synthesized carbon products. Fig. 8a shows a comparative TGA weight loss curve of the as-synthesized carbon materials synthesized over three sol-gel catalysts. It is considered that the weight loss up to $500^{\circ} \mathrm{C}$ can be assigned to the burning of amorphous carbon materials and further loss up to $700^{\circ} \mathrm{C}$ can be assigned to the oxidation of CNTs [41]. A slight weight gain in the case of the SG-1 catalyst at around $500^{\circ} \mathrm{C}$ is due to the oxidation of the catalytic metals; further weight loss can be assigned to the burning of CNTs. The results indicate that the weight loss percentages of t-MWCNTs due to SG-2 and SG-3 catalysts are around $85 \%$ and $82 \%$ from 500 to $650^{\circ} \mathrm{C}$, respectively. Before reaching the burning temperature, we were not able to see any significant weight loss in the TGA curve (Fig. 8a), which indicates that the as-synthesized t-MWCNTs consist of homogeneous carbon species without amorphous carbon. Interestingly, the differential thermogravimetric (DTG) curve of the as-synthesized CNTs from the SG-1 catalyst showed broad and weak peaks compared to the narrow width peaks from the SG-2 and SG-3 catalysts (Fig. 8b). The broadening of the DTG peak is attributed to the non-homogeneous structure of the CNTs, as confirmed by SEM and TEM observations. The TGA indicates that the t-MWCNTs synthesized by the SG-2 and SG-3 catalysts show homogeneity and purity higher than those of CNTs fabricated with the SG-1 catalyst.

Raman spectroscopy was used to further investigate the overall information of the as-synthesized CNTs. The Raman spectra of CNT materials synthesized by SG-1, SG-2, and SG-3 catalysts are shown in Fig. 9. In the Raman spectra, the G-band, which appears at approximately $\sim 1593 \mathrm{~cm}^{-1}$, is associated with $\mathrm{sp}^{2}$ hybridized carbon bonding (the in-plane stretching mode for graphene sheets), while the D-band at approximately $\sim 1350 \mathrm{~cm}^{-1}$ reveals the defect level, impurities, or lattice disordering in the graphite sheets. The peak intensity ratio of the $\mathrm{G}$ and D-bands

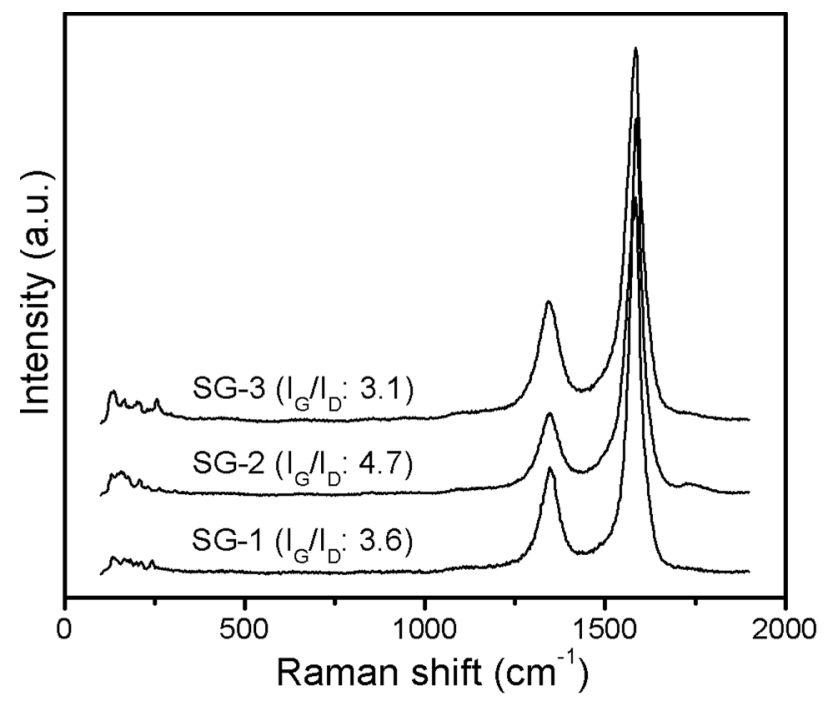

Fig. 9. Comparative Raman spectra of as-synthesized thin-multiwalled carbon nanotubes fabricated by SG-1, SG-2, and SG-3 catalysts.

$\left(\mathrm{I}_{\mathrm{G}} / \mathrm{I}_{\mathrm{D}}\right)$ is frequently used to understand the structure and quality of CNT samples [42,43]. In the case of the t-MWCNTs synthesized by the SG-2 and SG-3 catalysts, we can observe a high $\mathrm{I}_{\mathrm{G}} /$ $\mathrm{I}_{\mathrm{D}}$ ratio compared to that of the CNTs synthesized by the SG-1 catalyst, which indicates structural perfection and low defect levels. These results are in good agreement with our HRTEM observations.

\section{Conclusions}

We have demonstrated a new and simple fabrication method for $\mathrm{Fe}-\mathrm{Mo} / \mathrm{MgO}$ catalyst materials using a citrate precursor and based on the sol-gel technique; we achieve high-quality t-MWCNTs with uniform diameters by CCVD. A systematic investigation of the effect of the ambient type (air, $\mathrm{Ar}$, and $\mathrm{H}_{2}$ ) on the thermal decomposition of the citrate precursor in the fabrication of $\mathrm{Fe}-\mathrm{Mo} / \mathrm{MgO}$ catalysts and nanotube growth was carried out. The results suggest that, compared with an air atmosphere, $\mathrm{Ar}$ and $\mathrm{H}_{2}$ atmospheres were beneficial to achieving homogeneous and highly-dispersed $\mathrm{Fe}-\mathrm{Mo} / \mathrm{MgO}$ catalyst materials. Furthermore, uniformly distributing a lot of catalyst particles over the support material and effectively doping a high Mo content were the key parameters in the synthesis of homogeneous and high-quality t-MWCNTs on a large scale. In terms of chemical composition, the higher Mo content for the $\mathrm{Fe}-\mathrm{Mo} / \mathrm{MgO}$ catalyst induced a higher product yield and uniformity of the synthesized t-MWCNTs. It is suggested that the higher Mo content effectively promotes aromatization of $\mathrm{CH}_{4}$ and increases homogenously dispersed catalytic Fe sites over the support material, which results in an effective shielding against agglomeration at reaction temperature. The carbon materials mostly consisted of individual t-MWCNTs that were nearly free of defects, and amorphous carbon deposits on the nanotube surfaces. The outer tube diameters and the graphene walls of the as-synthesized tMWCNTs over the SG-2 catalyst were in the range of 4-8 nm (average dia. $\sim 6.6 \mathrm{~nm}$ ) and had graphene numbers in the range 
of 4-7. In this work, the as-synthesized t-MWCNTs showed a high product yield of over $450 \%$ relative to the utilized Fe-Mo/ $\mathrm{MgO}$ catalyst and a high purity of about $85 \%$.

\section{Acknowledgements}

This work was supported by, and supported by the Korea Foundation for International Cooperation of Science and Technology (KICOS) through a grant provided by the MOST in K20601000002-07E0100-00220, and supported by the Korea Basic Science Institute (KBSI).

\section{References}

[1] Jeong HD, Lee JH, Lee BG, Jeong HJ, Lee GW, Bang DS, Cho DH, Park YB, Jhee KH. Effect of few-walled carbon nanotube crystallinit on electron field emission property. Carbon Letters, 11, 207, (2011). http://dx.doi.org/CL.2011.12.4.207.

[2] Jeong HJ, Choi HK, Kim GY, Song YI, Tong Y, Lim SC, Lee YH. Fabrication of efficient field emitters with thin multiwalled carbon nanotubes using spray method. Carbon, 44, 2689 (2006). http:// dx.doi.org/10.1016/j.carbon.2006.04.009.

[3] Yuan H, Shin DH, Kim B, Lee CJ. Synthesis of well-aligned thin multiwalled carbon nanotubes on the silicon substrate and their field emission properties. Carbon Letters, 12, 218 (2011). http:// dx.doi.org/CL.2011.12.4.218.

[4] Jeong HJ, Kim KK, Jeong SY, Park MH, Yang CW, Lee YH. Highyield catalytic synthesis of thin multiwalled carbon nanotubes. J Phys Chem B, 108, 17695 (2004). http://dx.doi.org/10.1021/ jp046152o.

[5] Zhou LP, Ohta K, Kuroda K, Lei N, Matsuishi K, Gao L, Matsumoto T, Nakamura J. Catalytic functions of $\mathrm{Mo} / \mathrm{Ni} / \mathrm{MgO}$ in the synthesis of thin carbon nanotubes. J Phys Chem B, 109, 4439 (2005). http://dx.doi.org/10.1021/jp045284e.

[6] Qi H, Qian C, Liu J. Synthesis of high-purity few-walled carbon nanotubes from ethanol/methanol mixture. Chem Mater, 18, 5691 (2006). http://dx.doi.org/10.1021/cm061528r.

[7] Flahaut E, Peigney A, Laurent C, Rousset A. Synthesis of singlewalled carbon nanotube-Co-MgO composite powders and extraction of the nanotubes. J Mater Chem, 10, 249 (2000). http://dx.doi. org/10.1039/A908593I.

[8] Li Y, Liu J, Wang Y, Wang ZL. Preparation of monodispersed FeMo nanoparticles as the catalyst for CVD synthesis of carbon nanotubes. Chem Mater, 13, 1008 (2001). http://dx.doi.org/10.1021/ cm000787s.

[9] Jodin L, Dupuis AC, Rouviere E, Reiss P. Influence of the catalyst type on the growth of carbon nanotubes via methane chemical vapor deposition. J Phys Chem B, 110, 7328 (2006). http://dx.doi. org/10.1021/jp056793z.

[10] Deshpande K, Mukasyan A, Varma A. Direct synthesis of iron oxide nanopowders by the combustion approach: reaction mechanism and properties. Chem Mater, 16, 4896 (2004). http://dx.doi. org/10.1021/cm040061m.

[11] Coquay P, De Grave E, Peigney A, Vandenberghe RE, Laurent C. Carbon nanotubes by a CVD method. Part I: synthesis and characterization of the $(\mathrm{Mg}, \mathrm{Fe}) \mathrm{O}$ catalysts. J Phys Chem B, 106, 13186 (2002). http://dx.doi.org/10.1021/jp026631s.
[12] Coquay P, Peigney A, De Grave E, Vandenberghe RE, Laurent C. Carbon nanotubes by a CVD method. Part II: formation of nanotubes from (Mg, Fe)O catalysts. J Phys Chem B, 106, 13199 (2002). http://dx.doi.org/10.1021/jp026632k.

[13] Flahaut E, Peigney A, Bacsa WS, Bacsa RR, Laurent C. CCVD synthesis of carbon nanotubes from $(\mathrm{Mg}, \mathrm{Co}, \mathrm{Mo}) \mathrm{O}$ catalysts: influence of the proportions of cobalt and molybdenum. J Mater Chem, 14, 646 (2004). http://dx.doi.org/10.1039/B312367G.

[14] Alvarez WE, Kitiyanan B, Borgna A, Resasco DE. Synergism of $\mathrm{Co}$ and Mo in the catalytic production of single-wall carbon nanotubes by decomposition of CO. Carbon, 39, 547 (2001). http:// dx.doi.org/10.1016/s0008-6223(00)00173-1.

[15] Ning Y, Zhang X, Wang Y, Sun Y, Shen L, Yang X, Van Tendeloo G. Bulk production of multi-wall carbon nanotube bundles on sol-gel prepared catalyst. Chem Phys Lett, 366, 555 (2002). http:// dx.doi.org/10.1016/s0009-2614(02)01647-0.

[16] Shajahan M, Mo YH, Fazle Kibria AKM, Kim MJ, Nahm KS. High growth of SWNTs and MWNTs from $\mathrm{C}_{2} \mathrm{H}_{2}$ decomposition over $\mathrm{Co}-\mathrm{Mo} / \mathrm{MgO}$ catalysts. Carbon, 42, 2245 (2004). http:// dx.doi.org/10.1016/j.carbon.2004.04.038.

[17] Perez-Mendoza M, Valles C, Maser WK, Martinez MT, Benito AM. Influence of molybdenum on the chemical vapour deposition production of carbon nanotubes. Nanotechnology, 16, S224 (2005). http://dx.doi.org/10.1088/0957-4484/16/5/016.

[18] Ward DA, Ko EI. Preparing catalytic materials by the sol-gel method. Ind Eng Chem Res, 34, 421 (1995). http://dx.doi.org/10.1021/ ie00041a001.

[19] Dubey P, Choi SK, Choi JH, Shin DH, Lee CJ. High-quality thinmultiwalled carbon nanotubes synthesized by $\mathrm{Fe}-\mathrm{Mo} / \mathrm{MgO}$ catalyst based on a solgel technique: synthesis, characterization, and field emission. J Nanosci Nanotechnol, 10, 3998 (2010). http:// dx.doi.org/10.1166/jnn.2010.1984

[20] Zhou ZH, Deng YF, Cao ZX, Zhang RH, Chow YL. Dimeric dioxomolybdenum(VI) and oxomolybdenum(V) complexes with citrate at very low $\mathrm{pH}$ and neutral conditions. Inorg Chem, 44, 6912 (2005). http://dx.doi.org/10.1021/ic048330y.

[21] Wang JA, Novaro O, Bokhimi X, Lopez T, Gomez R, Navarrete J, Llanos ME, Lopez-Salinas E. Structural defects and acidic and basic sites in sol-gel MgO. J Phys Chem B, 101, 7448 (1997). http:// dx.doi.org/10.1021/jp9702331.

[22] Hu YH, Ruckenstein E. Binary MgO-based solid solution catalysts for methane conversion to syngas. Catal Rev, 44, 423 (2002). http://dx.doi.org/10.1081/cr-120005742.

[23] Li Y, Zhang X, Tao X, Xu J, Chen F, Huang W, Liu F. Growth mechanism of multi-walled carbon nanotubes with or without bundles by catalytic deposition of methane on $\mathrm{Mo} / \mathrm{MgO}$. Chem Phys Lett, 386, 105 (2004). http://dx.doi.org/10.1016/j.cplett.2003.12.128.

[24] Wang HM, Wang XH, Zhang MH, Du XY, Li W, Tao KY. Synthesis of bulk and supported molybdenum carbide by a single-step thermal carburization method. Chem Mater, 19, 1801 (2007). http://dx.doi.org/10.1021/cm0615471.

[25] Hua Z, Bu W, Lian Y, Chen H, Li L, Zhang L, Li C, Shi J. Postgrafting preparation of large-pore mesoporous materials with localized high content titanium doping. J Mater Chem, 15, 661 (2005). http://dx.doi.org/10.1039/B413478H.

[26] Ma W, Kugler EL, Wright J, Dadyburjor DB. Mo-Fe catalysts supported on activated carbon for synthesis of liquid fuels by the Fischer-Tropsch process: effect of Mo addition on reducibility, activity, and hydrocarbon selectivity. Energy Fuels, 20, 2299 (2006). 
http://dx.doi.org/10.1021/ef0602372.

[27] Hu M, Murakami Y, Ogura M, Maruyama S, Okubo T. Morphology and chemical state of Co-Mo catalysts for growth of single-walled carbon nanotubes vertically aligned on quartz substrates. J Catal, 225, 230 (2004). http://dx.doi.org/10.1016/j.jcat.2004.04.013.

[28] Herrera JE, Balzano L, Borgna A, Alvarez WE, Resasco DE. Relationship between the structure/composition of Co-Mo catalysts and their ability to produce single-walled carbon nanotubes by CO disproportionation. J Catal, 204, 129 (2001). http://dx.doi. org/10.1006/jcat.2001.3383.

[29] Quincy RB, Houalla M, Proctor A, Hercules DM. Distribution of molybdenum oxidation states in reduced molybdenum/titania catalysts: correlation with benzene hydrogenation activity. J Phys Chem, 94, 1520 (1990). http://dx.doi.org/10.1021/j100367a058.

[30] Katrib A, Leflaive P, Hilaire L, Maire G. Molybdenum based catalysts. I. $\mathrm{MoO}_{2}$ as the active species in the reforming of hydrocarbons. Catal Lett, 38, 95 (1996). http://dx.doi.org/10.1007/ bf00806906.

[31] Solymosi F, Cserenyi J, Szoke A, Bansagi T, Oszko A. Aromatization of methane over supported and unsupported Mo-based catalysts. J Catal, 165, 150 (1997). http://dx.doi.org/10.1006/ jcat.1997.1478.

[32] Muller A, Sarkar S, Shah SQN, Bogge H, Schmidtmann M, Sarkar S, Kogerler P, Hauptfleisch B, Trautwein AX, Schunemann V. Archimedean synthesis and magic numbers: "sizing" giant molybdenum-oxide-based molecular spheres of the Keplerate type. Angew Chem Int Ed, 38, 3238 (1999). http://dx.doi.org/10.1002/ (sici)1521-3773(19991102)38:21<3238::aid-anie3238>3.0.co;2-6.

[33] Muller A, Krickemeyer E, Das SK, Kogerler P, Sarkar S, Bogge H, Schmidtmann M, Sarkar S. Linking icosahedral, strong molecular magnets $\{\mathrm{Mo}\}$ to layers - a solid-state reaction at room temperature. Angew Chem Int Ed, 39, 1612 (2000). http:// dx.doi.org/10.1002/(sici)1521-3773(20000502)39:9<1612::aidanie1612>3.0.co;2-1.

[34] Herrera JE, Resasco DE. Loss of single-walled carbon nanotubes selectivity by disruption of the Co-Mo interaction in the catalyst. J Catal, 221, 354 (2004). http://dx.doi.org/10.1016/j. jcat.2003.08.005.

[35] Auvray N, Braunstein P, Mathur S, Veith M, Shen H, Hufner S. Thin films by metal organic deposition of Fe-Mo-S molecular clusters: synthesis and crystal structure of $\left[\mathrm{Cp}_{2} \mathrm{MoFe}_{2}\left(\mu_{3}-\mathrm{S}\right)_{2}(\mathrm{CO})_{6}\right]$. New J Chem, 27, 155 (2003). http://dx.doi.org/10.1039/B206923G.

[36] Hoor FS, Tharamani CN, Ahmed MF, Mayanna SM. Electrochemical synthesis of $\mathrm{Fe}-\mathrm{Mo}$ and $\mathrm{Fe}-\mathrm{Mo}-\mathrm{Pt}$ alloys and their electrocatalytic activity for methanol oxidation. J Power Sources, 167, 18 (2007). http://dx.doi.org/10.1016/j.jpowsour.2007.01.089.

[37] Wang L, Tao L, Xie M, Xu G, Huang J, Xu Y. Dehydrogenation and aromatization of methane under non-oxidizing conditions. Catal Lett, 21, 35 (1993). http://dx.doi.org/10.1007/bf00767368.

[38] Solymosi F, Nemeth R, Ovari L, Egri L. Reactions of propane on supported Mo2C catalysts. J Catal, 195, 316 (2000). http://dx.doi. org/10.1006/jcat.2000.3000.

[39] Shu Y, Ichikawa M. Catalytic dehydrocondensation of methane towards benzene and naphthalene on transition metal supported zeolite catalysts: templating role of zeolite micropores and characterization of active metallic sites. Catal Today, 71, 55 (2001). http:// dx.doi.org/10.1016/s0920-5861(01)00440-0.

[40] Cassell AM, Raymakers JA, Kong J, Dai H. Large scale CVD synthesis of single-walled carbon nanotubes. J Phys Chem B, 103, 6484 (1999). http://dx.doi.org/10.1021/jp990957s.

[41] Chiang IW, Brinson BE, Huang AY, Willis PA, Bronikowski MJ, Margrave JL, Smalley RE, Hauge RH. Purification and characterization of single-wall carbon nanotubes (SWNTs) obtained from the gas-phase decomposition of CO (HiPco process). J Phys Chem B, 105, 8297 (2001). http://dx.doi.org/10.1021/jp0114891.

[42] Bacsa WS, Ugarte D, Châtelain A, de Heer WA. High-resolution electron microscopy and inelastic light scattering of purified multishelled carbon nanotubes. Phys Rev B, 50, 15473 (1994). http:// dx.doi.org/10.1103/PhysRevB.50.15473.

[43] Tohji K, Goto T, Takahashi H, Shinoda Y, Shimizu N, Jeyadevan B, Matsuoka I, Saito Y, Kasuya A, Ohsuna T, Hiraga K, Nishina Y. Purifying single-walled nanotubes. Nature, 383, 679 (1996). http:// dx.doi.org/10.1038/383679a0. 